\title{
Population-based emergence of unfamiliar climates
}

Article

Accepted Version

Frame, D., Joshi, M., Hawkins, E., Harrington, L. J. and de Roiste, M. (2017) Population-based emergence of unfamiliar climates. Nature Climate Change, 7 (6). pp. 407-411. ISSN 1758-678X doi: https://doi.org/10.1038/nclimate3297 Available at https://centaur.reading.ac.uk/70479/

It is advisable to refer to the publisher's version if you intend to cite from the work. See Guidance on citing.

Published version at: http://dx.doi.org/10.1038/nclimate3297

To link to this article DOI: http://dx.doi.org/10.1038/nclimate3297

Publisher: Nature Publishing Group

All outputs in CentAUR are protected by Intellectual Property Rights law, including copyright law. Copyright and IPR is retained by the creators or other copyright holders. Terms and conditions for use of this material are defined in the End User Agreement.

\section{www.reading.ac.uk/centaur}

\section{CentAUR}

Central Archive at the University of Reading

Reading's research outputs online 


\section{Population-based emergence of unfamiliar climates}

Dave Frame ${ }^{1,2}$, Manoj Joshi ${ }^{3}$, Ed Hawkins ${ }^{4}$, Luke J. Harrington ${ }^{1,2}$ and Mairead de Roiste ${ }^{1}$

${ }^{1}$ New Zealand Climate Change Research Institute, Victoria University of Wellington, Wellington 6012, New Zealand

${ }^{2}$ National Institute of Water and Atmospheric Research, Wellington 6021, New Zealand

${ }^{3}$ Climatic Research Unit, School of Environmental Sciences, University of East Anglia, UK

${ }^{4}$ National Centre for Atmospheric Science, University of Reading, UK

Correspondence address:

Dave Frame

New Zealand Climate Change Research Institute

Victoria University of Wellington

PO Box 600

Wellington

New Zealand

Email address: david.frame@vuw.ac.nz 
Time of Emergence' (ToE), which characterizes when significant signals of climate change will emerge from existing variability, is a useful and increasingly common metric $^{1-3}$. However, a more useful metric for understanding future climate change in the context of past experience may be the ratio of climate signal to noise $(\mathrm{S} / \mathrm{N})$ - a measure of the amplitude of change expressed in terms of units of existing variability. Here, we present $\mathbf{S} / \mathbf{N}$ projections in the context of emergent climates (termed 'unusual', 'unfamiliar' and 'unknown' by reference to an individual's lifetime), highlighting sensitivity to future emissions scenarios and geographical and human groupings. We show how for large sections of the world's population, and for several geopolitical international groupings, mitigation can delay the onset of 'unknown' or 'unfamiliar' climates by decades, and perhaps even beyond 2100 . Our results demonstrate that the benefits of mitigation accumulate over several decades, a key metric for such benefits is reducing $S / N$, or keeping climate as familiar as possible, and that a relationship exists between cumulative emissions and patterns of emergent climate signals. Timely mitigation will therefore provide the greatest benefits to those facing the earliest impacts, many of whom are alive now.

\section{Main Text}

We illustrate the effect of $\mathrm{S} / \mathrm{N}$ on the degree of unfamiliarity that a new climate has using a Gaussian distribution as an example (see methods). The curves in Figure 1a show the relationship between climates passing different integer $\mathrm{S} / \mathrm{N}$ values (denoted as $\mathrm{SN} 1, \mathrm{SN} 2$, SN3 respectively) compared to a "base" period. Panel 1a shows that at SN1, temperatures are unusual, but not unfamiliar - in the sense that they overlap with the base period approximately $62 \%$ of the time, and that years warmer than the new mean would have been experienced once every 6 years or so under the base climate - hence we denote SN1 as the 
threshold for an "unusual" climate. At SN2 the overlap drops to $32 \%$, implying that the coldest three years out of every ten in the warmer climate are the same as the warmest three years out of ten in the base period, but importantly the mean is warmer than $98 \%$ of base period years - hence SN2 is denoted "unfamiliar" in that the new climate would occur as a 1in-44 year event under the older base climate. By SN3 the overlap between coldest projected years and warmest base period years is only $13 \%$, but the new mean climate is warmer than $99.9 \%$ of the base years; this mean climate state is "unknown" in the sense that it would be experienced on average once every 740 years in the base climate, i.e. far beyond a human lifetime.

Recent work ${ }^{4,5}$ considered the fraction of the global population crossing particular integer $\mathrm{S} / \mathrm{N}$ values in future. Panels $1 \mathrm{~b}$ and $1 \mathrm{c}$ compare this global population-based metric with fraction of global surface area passing SN1 (pink curve); SN2; (red curve) and SN3 (maroon) for RCP4.5. Thick central curves mark the middle of the CMIP5 ensemble; bands represent the $16-84 \%$ range of CMIP5 ensemble members. The vast majority of communities can expect to experience "unfamiliar" climates by 2060, even if TCR is low. If TCR is high, then the vast majority of human communities will experience unknown climates, i.e. $\mathrm{S} / \mathrm{N}>3$, by the 2040s.

Panel 1d highlights that the rate of emergence is faster for human populations than for surface area in each RCP; in other words climates change faster where people live than where they do not. Approximately $50 \%$ of the global population can expect to experience unfamiliar climates (relative to 1986-2005) by approximately 2030 and unknown climates by midcentury. Under the median RCP4.5 scenario, only $20 \%$ of people avoid living in unknown climates by 2100; as we show later, these people live in the extra-tropics. 
Increasing $\mathrm{S} / \mathrm{N}$ values implies increasing damages from climate change, a point amplified if, as many people argue ${ }^{6-9}$, climate change damages are convex functions of temperature change. This effect is likely to be more pronounced if change is fast than if societies have more time to adjust ${ }^{10}$. Where climate change impacts are sigmoidal ${ }^{11}$ rather than convex, impacts may asymptote to a fixed value beyond some $\mathrm{S} / \mathrm{N}$ level. However, even if this is the case the geographical sequencing of emergence with time is still robust. Although important institutional and geographical details may change the picture for certain regions and impacts, in general this suggests an urgent need to begin investing in adaptive capacity in those regions which are expected to experience unknown climates earliest.

These regions are highlighted in Figure 2, which shows conventional maps and populationweighted cartograms of late $21^{\text {st }}$-century (henceforth L21C) $\mathrm{S} / \mathrm{N}$ values for the representative concentration pathway RCP4.5. The cartograms distort geographical shapes by weighting the size of grid boxes by the number of people who live in that grid box, and are a novel way of differentiating human dimensions of climate emergence from geographical dimensions ${ }^{12}$. For example, while Figure 2a shows that some areas of the tropics are likely to experience unknown climates by L21C $\mathrm{C}^{2}$, Figure $2 \mathrm{c}$ emphasises that these regions are home to a significant fraction of the world's population, such as Malaysia/Indonesia, Western India, West Africa and Central America. Consistent with Figure 1d, Figure 2 shows that under the RCP4.5 scenario, a greater fraction of population than area experiences "unknown" climates by $\mathrm{L} 21 \mathrm{C}$, and that these people are predominantly in the tropics - a result that is more clearly displayed in cartograms than conventional maps.

Under RCP4.5 the range in emergence values by the end of the century is mainly associated with uncertainties in the climate response (defined using Transient Climate Response, or TCR), with a smaller contribution from the amplitude of simulated variability, which affects 
the estimated $\mathrm{S} / \mathrm{N}$ values ${ }^{3}$. Some caution should be exercised in interpreting the very high $\mathrm{S} / \mathrm{N}$ values in the tropics - models sometimes underestimate aspects of variability (issues discussed extensively in the Climate Model Evaluation Chapter of the most recent IPCC assessment $)^{13}$ and, coupled with the already small annual variability in tropical temperatures, this may inflate simulated tropical $\mathrm{S} / \mathrm{N}$ values. However, it should be stressed that while the details of extremely high tropical $\mathrm{S} / \mathrm{N}$ values should be interpreted cautiously, it does not affect our main conclusions, which are based on $\mathrm{S} / \mathrm{N}$ values of $2-3$, i.e. unfamiliar and unknown climates.

Figure 3 shows $\mathrm{S} / \mathrm{N}$ in the RCP8.5 and RCP2.6 scenarios, and the effect of mitigating emissions from the former to latter scenario for the $16^{\text {th }}$ and $84^{\text {th }}$ percentile of the CMIP5 ensemble. Figure 3 shows that under RCP 2.6, S/N has a high chance of staying below 3 over most parts of the world, in contrast to RCP 8.5, in which most areas are likely to exceed $\mathrm{S} / \mathrm{N}=3$ and experience "unknown climates" by L21C (Figure 3). The bottom two rows show where mitigating can make the greatest difference. Even in a low-TCR world, significant mitigation reduces $\mathrm{L} 21 \mathrm{C} \mathrm{S} / \mathrm{N}$ by 3 or more for large groups of people in the tropics. We suggest that a key measure of successful mitigation should involve keeping climate as 'familiar' as possible, and that the difference plots of Figure 3 represent a reasonable model of mitigation benefits measured in this manner. Interestingly, the qualitative patterns of the lower two rows of Figure 3 emerge if we compare any pairwise set of RCPs, implying that a relationship exists between $\mathrm{S} / \mathrm{N}$ and cumulative emissions of carbon, and that this relationship is essentially a matter of pattern scaling (on sufficiently large spatial scales), as is the case with other temperature-based climate variables ${ }^{14}$. Even though we are uncertain about the emissions trajectory under a world without climate policy and a world with a strong climate policy, we can be confident that the basic patterns summarized in Figure 3 describes 
the benefits of mitigation in terms of the emergence of climate change signals above variability.

The evolution of $\mathrm{S} / \mathrm{N}$ in time highlights the speed at which large groups of countries start to experience 'unknown' or 'unfamiliar' climates. Figure 4 considers such a selection of international groups with spatial scales large enough to be represented in GCMs, but with very diverse economic and social characteristics: "AOSIS"- the Association of Small Island States; "ASEAN" - the Association of South-East Asian Nations; "LDCs" - countries considered to be least developed (the "bottom billion" "15,16); "GEMs" - Global Emerging Markets ${ }^{17}$ (those G20 countries not in the OECD90 group ${ }^{17}$ ); "OECD90” (all member countries of the Organization for Economic Cooperation and Development as of 1990). The curves in Figure 4 show cumulative distributions of population experiencing successive values of $\mathrm{S} / \mathrm{N}$, grouped by the above international groups, and by RCP scenario.

The gains from mitigating from RCP 8.5 (red) to RCP 2.6 (blue) are shown on the right hand side column in orange. The blue curves in Figure 4 corresponding to RCP2.6 can also be considered a proxy for the minimum level of emergent temperature change to which people will have to adapt, unless mitigation strategies even more aggressive than those considered in RCP 2.6 are adopted. What is clear is that with levels of mitigation equivalent to RCP2.6, most people's climates in OECD90 and GEM can be prevented from ever becoming "unknown". Additionally, even though this is not the case for tropical groupings such as ASEAN and AOSIS, mitigation is arguably just as important here, if not even more, since the difference between $\mathrm{S} / \mathrm{N} \sim 4$ under $\mathrm{RCP} 2.6$ and $\mathrm{S} / \mathrm{N}>10$ under $\mathrm{RCP} 8.5$ represents a very large amount of change-in-the-context-of-variability avoided.

Even if RCP8.5 is too pessimistic to warrant being considered the starting point for mitigation the overall pattern of emergence avoided by mitigation (i.e. the benefits of 
mitigation) still resembles a scaled version of the right-hand column of Figure 4 irrespective of the exact details of the scenario used to portray worlds without climate mitigation. More extensive results for regional economic groups, security-related groups, and climate negotiation blocs are presented in the Supplementary Information (Figure S5).

The larger values of $\mathrm{S} / \mathrm{N}$ in groups such as AOSIS (Figure 4a) compared to OECD90 (Figure 4i) imply that the former grouping experiences earlier emergence of unusual or unfamiliar climates than the latter. Such relatively early change is likely to affect other places through economic, security or political spillover effects, especially where early climate impacts contribute to security and humanitarian issues in vulnerable countries or where trade in goods vulnerable to climate change is significant. Such groupings can be thought of as earliest common denominators of emergent change: patterns of emergent climate change within them affect those groups where ToEs are much later, depending on the strengths of the interactions between such groups.

Policymakers and scholars are sometimes under the mistaken impression that benefits of mitigation are remote: "[ $\mathrm{t}]$ he time lag is at the very least longer than the lifetime of any adult. The upshot is that no one who is asked to curtail activities to reduce greenhouse gas concentrations will be likely to live long enough to enjoy the benefits of that curtailment"18; and "Mitigation will have global benefits but, owing to the lag times in the climate and biophysical systems, these will hardly be noticeable until around the middle of the 21 st century" (IPCC AR4 TS 5.2). Our analysis demonstrates that vast numbers of potential beneficiaries of climate policy are alive today: assuming that climate emergence scales approximately with cumulative emissions, in a high carbon future (RCP 8.5), today's young adults in the OECD90 group for example can expect to find only one year in two familiar from their childhoods by mid-century. For citizens of AOSIS or the LDCs, the picture is 
starker still. However, emergence everywhere is greatly reduced and delayed under a low carbon future, such as RCP2.6. Our analysis shows that near-term mitigation initiatives can prevent many climates from becoming radically different from those experienced in the recent past, that such effects happen well within a human lifetime, and that this is especially true for those whose communities would otherwise change fastest. In other words, many of the long-term benefits of mitigation can be internalized by many people alive today.

\section{Methods}

This study compares ensembles of models from the CMIP5 experiment run under representative concentration pathway $(\mathrm{RCP})$ scenarios $^{15}$. We estimate $\mathrm{S} / \mathrm{N}$ for near-surface air temperature following previous published methods $^{3}$ (and Kirtman et al. 2013, IPCC AR5 Chapter 11), using the CMIP5 simulations for the 25 models which ran each of RCP2.6, 4.5 $\& 8.5$ scenarios, and presented relative to a baseline climate of 1986-2005.

To obtain the $16^{\text {th }}$ and $84^{\text {th }}$ percentile, models are ordered from low to high, and we select the model which comes closest to representing a 16th and 84th percentile rank. So for the 25 models used for the figures (which had data across all 3 RCPs), we have selected the models which were ranked numbers 4 and 21 (with 1 being lowest $\mathrm{S} / \mathrm{N}, 25$ being highest). This is done at each grid point.

Signals are diagnosed by calculating the global mean surface air temperature (SAT) and fitting a 4th-order polynomial (GMST), then regressing gridpoint SAT against smoothed GMST using the whole time-series to derive a smoothed gridpoint signal which is proportional to the global mean. The 1986-2005 mean is then removed from the smoothed gridpoint data. The $\mathrm{N}$ term is the standard deviation of annual mean temperatures in the control runs at each grid point. ${ }^{3}$ 
Note that warming before 1986-2005 would add to the $\mathrm{S} / \mathrm{N}$ values shown in this analysis. Population and national boundary data are from the CIESIN dataset. We overlay the national boundary mask from CIESIN on the population dataset to obtain the number of residents in each $1 / 4^{\circ}$ grid box (both the population data and the national boundary data have this resolution). Where there are multiple countries within a dataset we apportion the population evenly between them. This introduces small inaccuracies, but these are negligible at the international and normalized scales on which the paper focuses. We then aggregate the appropriate national population data onto the lower resolution grid of the climate model output. We do this for each of the CMIP5 models for which data are available under the three scenarios considered here. This gives us both a number of people (in each climate model grid box) and a $\mathrm{S} / \mathrm{N}$ (for each climate model grid box and year) for each model, for each scenario. Population changes over timescales relevant to this analysis, but there is uncertainty surrounding exactly how and where it will change the most. The presented analysis assumes 2015 population levels throughout, but we repeated the analysis for the 2000 distribution of population to consider how recent demographic change interacts with emergent climate change (see Figure S7). Essentially the results are very similar under both population distributions.

An important caveat is that natural variability places significant limits on our ability to give detailed estimates of exactly when climates cross integer $\mathrm{S} / \mathrm{N}$ values, with both the simulation of natural variability and the models' ability to capture anthropogenic change playing a role in determining the time of emergence of climate signals ${ }^{17}$. In particular we note that global temperatures did not warm as fast as the mean of the CMIP5 models in the early $21^{\text {st }}$ Century $^{18}$, likely due to natural radiative forcings not included in the simulations, internal climate variability, a relatively low TCR, or a combination thereof. This slowdown implies that, on average, the very earliest projected emergence dates are likely to be slightly delayed. 


\section{Acknowledgements}

DJF, LJH and MMJ acknowledge support from Victoria University of Wellington. EH and MMJ acknowledge support from NCAS Climate. DJF and LJH acknowledge support from the Deep South National Science Challenge. EH is funded by a UK NERC Research Fellowship. The authors thank Sam Dean and Suzanne Rosier for informative discussions, and thank the reviewers.

\section{Author contributions}

MMJ and DJF conceived the project. DJF, EH and LJH performed the analysis, and MdR produced the cartograms and maps. All authors wrote the paper. 
(a)

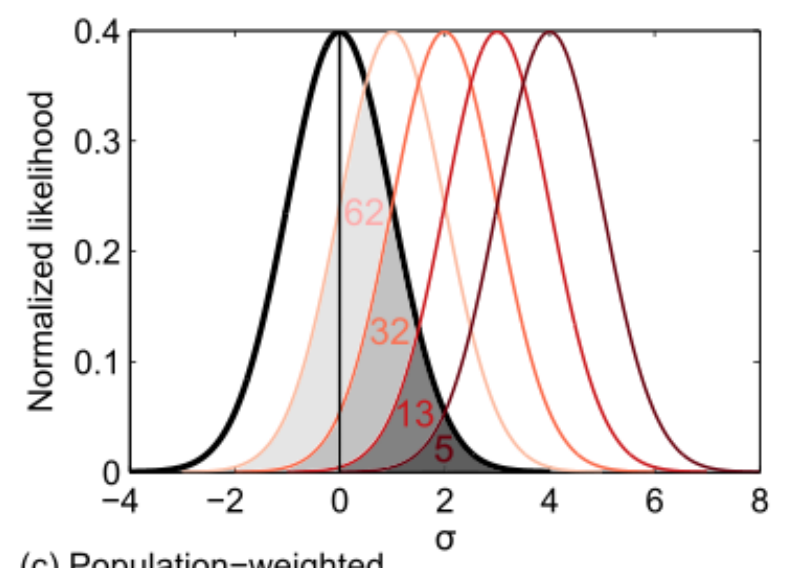

(c) Population-weighted

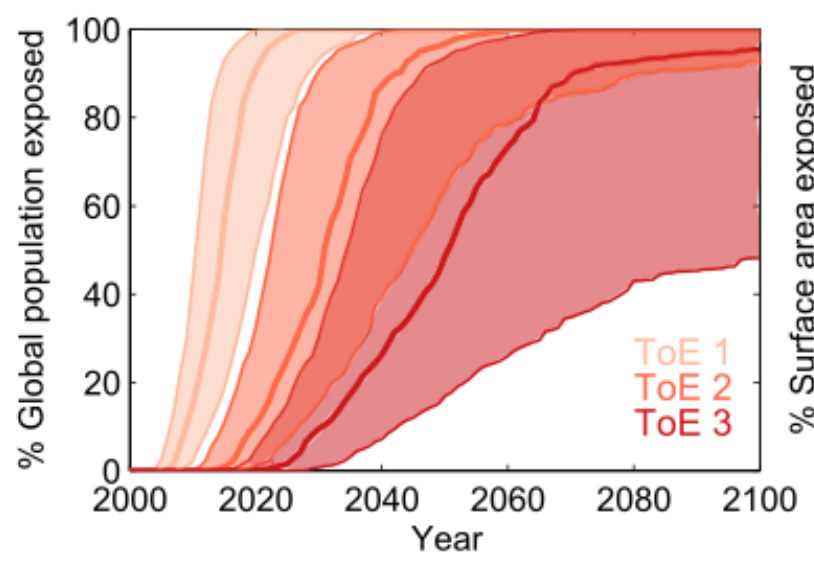

(b) Area-weighted

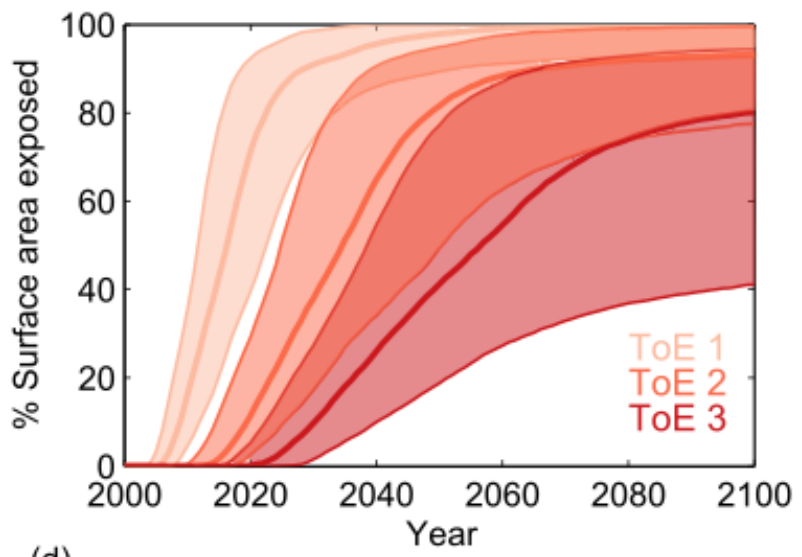

(d)

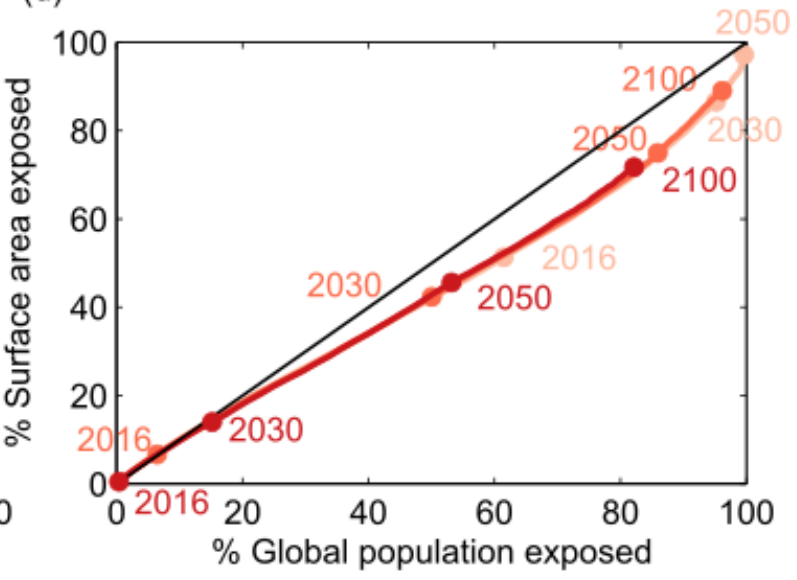

Figure 1: Schematic of the first four successive integer $\mathrm{S} / \mathrm{N}$ values for a Gaussian distribution (panel a). Also shown in panel (a) are the fraction of the new distribution at successive integer $\mathrm{S} / \mathrm{N}$ values which remains from the original distribution. Overlap between the base distribution and the distribution at successive standard deviation shifts of integer $\mathrm{S} / \mathrm{N}$ values are shown as the grey segments - note that these are cumulative, i.e. in a shift from the base to the first $\mathrm{S} / \mathrm{N}$ threshold the overlap includes all the grey segments. Panel (b) shows the cumulative fraction of the world's surface area passing S/N1-3 under RCP4.5; panel (c) shows the cumulative fraction of the world's population passing S/N1-3 under RCP4.5. Panel (d) shows the median rate at which cumulative fraction of global surface area passes SN1-3 compared with the median rate at which the cumulative fraction of the global population passes these thresholds. 
RCP 4.5

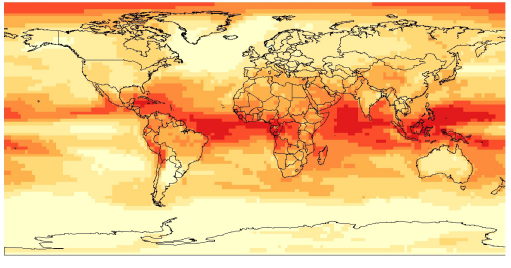

16th percentile CMIP5 ensemble

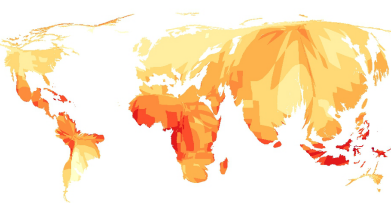

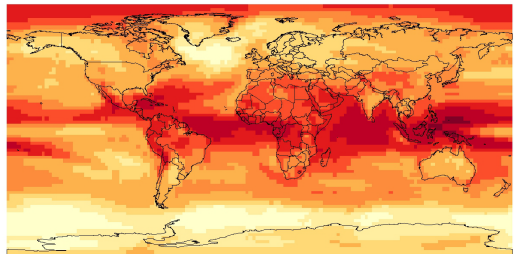

50th percentile CMIP5 ensemble

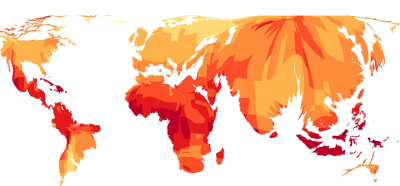

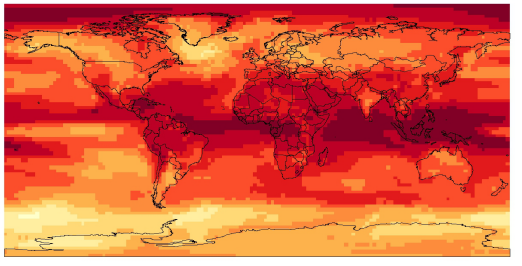

84th percentile CMIP5 ensemble

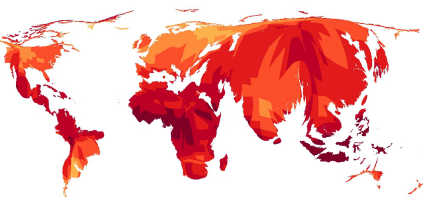

$\begin{array}{llllllllll}0 & 1.6 & 2.2 & 2.8 & 3.6 & 4.4 & 5.4 & 6.7 & 9.0 & 25.5\end{array}$

Figure 2: Maps (top row) of modelled annual mean $\mathrm{S} / \mathrm{N}$ for the median (central column), and $16^{\text {th }}$ (left-hand column) and $84^{\text {th }}$ (right-hand column) percentiles of the CMIP5 models under the RCP4.5 scenario, and corresponding population-based cartograms (bottom row). 

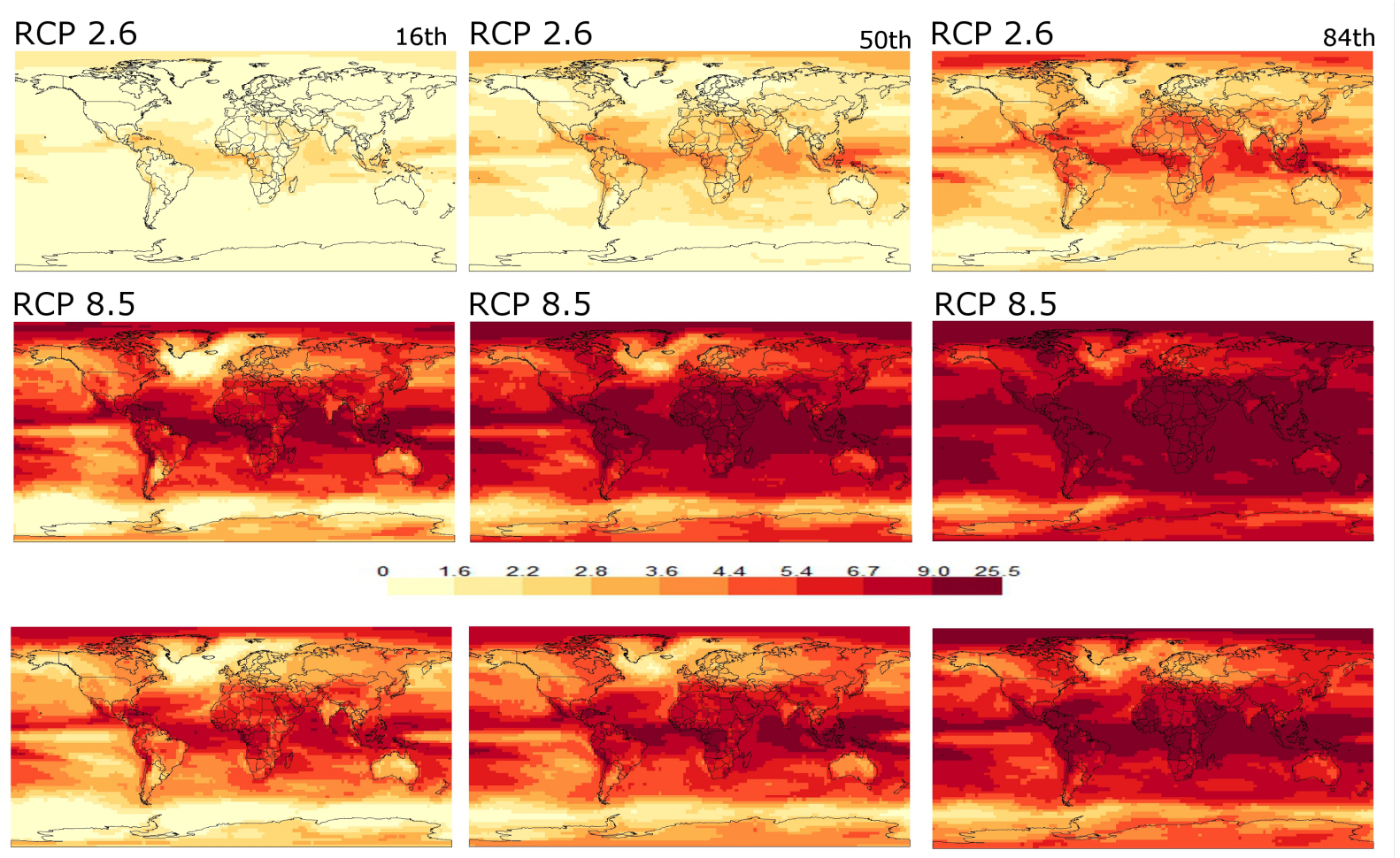

RCP $8.5-$ RCP 2.6

RCP $8.5-$ RCP 2.6

RCP $8.5-$ RCP 2.6
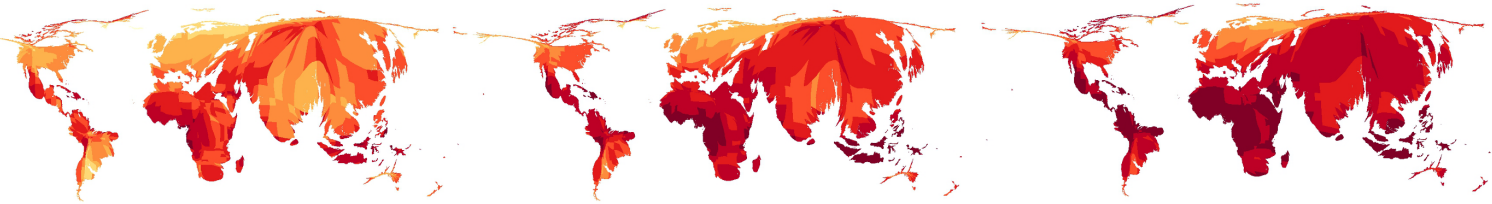

Figure 3: Top row: maps of modelled annual mean $\mathrm{S} / \mathrm{N}$ values for the end of the $21^{\text {st }}$ Century (2071-2100) for the $16^{\text {th }}$ and $84^{\text {th }}$ percentiles of the RCP2.6 scenario. Second row: as for the top row but for the RCP8.5 scenario. Third row: RCP8.5 minus 2.6, or, the $\mathrm{S} / \mathrm{N}$ avoided by mitigation from RCP8.5 to 2.6. Bottom row: As for the third row, but displayed as population-based cartograms to better illustrate the human dimension of avoiding high values of $\mathrm{S} / \mathrm{N}$. Not all modelling groups ran all scenarios, so in this analysis we have only considered those models which ran both RCP 8.5 and RCP 2.6 (a total of 25 models), so that we would be making a like for like comparison in terms of ensemble members (see Figure S3). The data are displayed on a common scale. 
(a) AOSIS
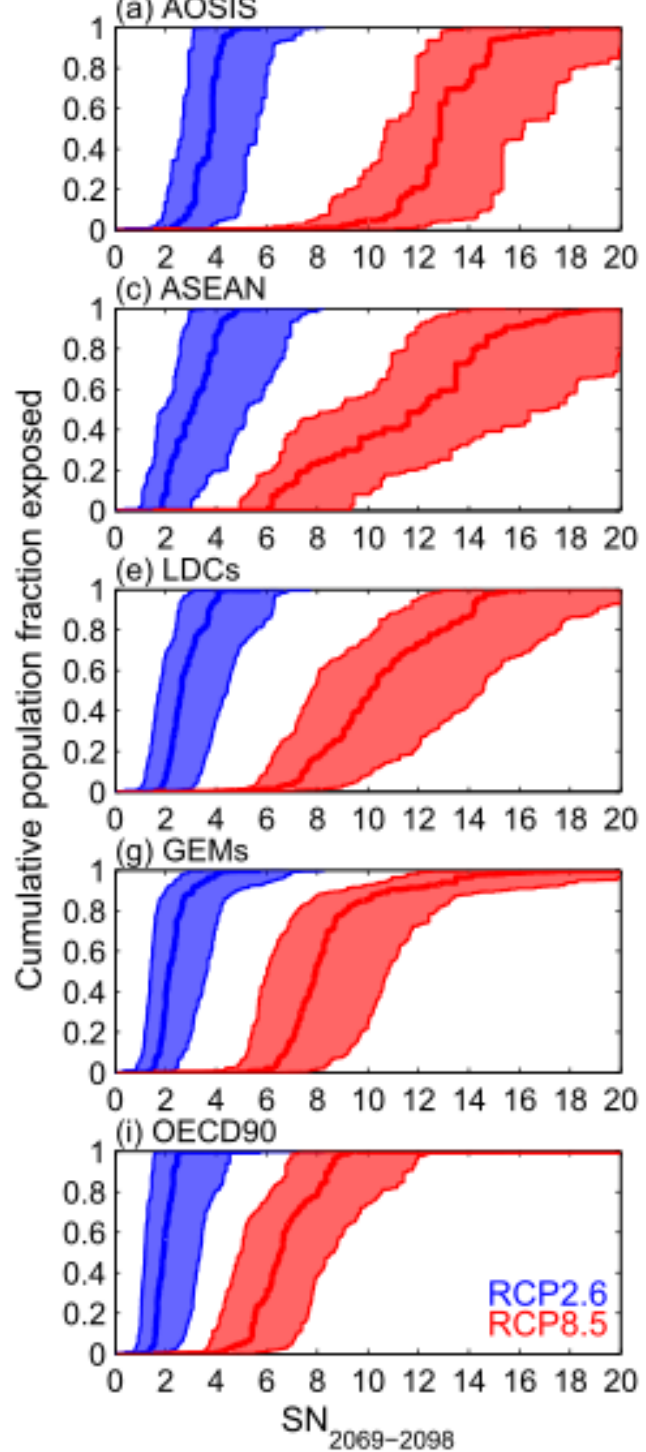

(b) AOSIS

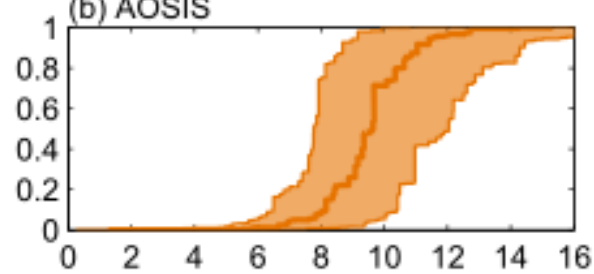

(d) ASEAN
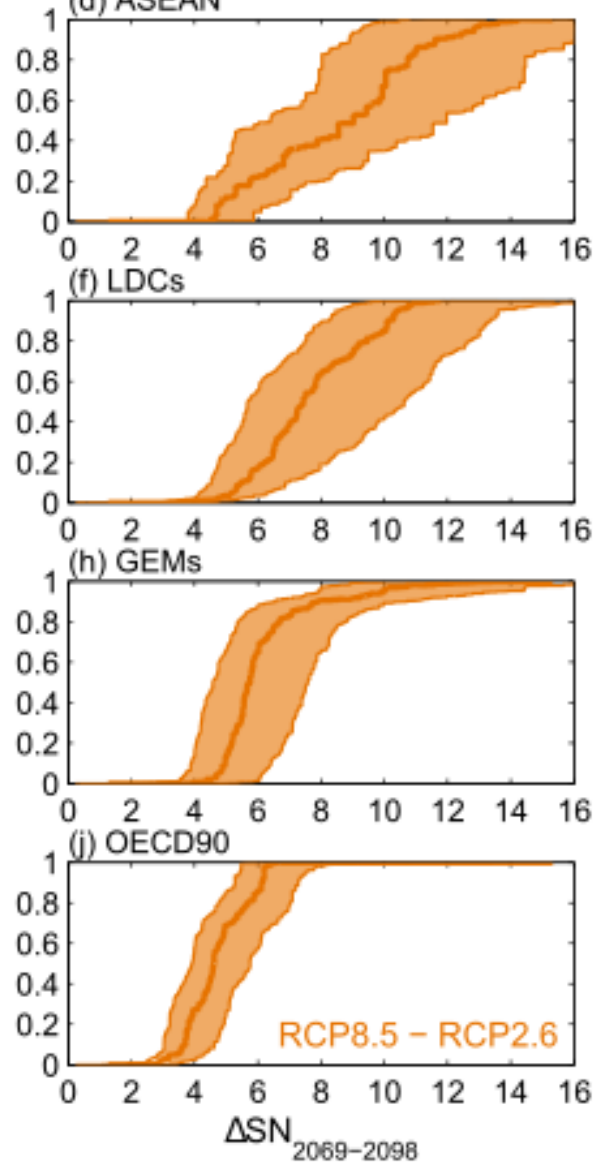

Figure 4: $\mathrm{S} / \mathrm{N}$ values versus cumulative fraction of population in different international groups under RCP2.6 (blue), RCP8.5 (red) and the difference between these (orange displayed in right hand column). Median values are shown as central solid lines; bands represent the $16^{\text {th }}-84^{\text {th }}$ percentile of models in the CMIP5 ensemble. Additional groups are shown in the Supplementary information.

\section{References}

1 Giorgi, F. \& Bi, X. Time of emergence (TOE) of GHG-forced precipitation change hot-spots. Geophysical Research Letters 36, n/a-n/a, doi:10.1029/2009GL037593 (2009). 

significant local warming in low latitude countries. Environmental Research Letters 6, 034009 (2011).

3 Hawkins, E. \& Sutton, R. Time of emergence of climate signals. Geophysical Research Letters 39, n/a-n/a, doi:10.1029/2011GL050087 (2012).

4 Lehner, F. \& Stocker, T. F. From local perception to global perspective. Nature Clim. Change 5, 731-734, doi:10.1038/nclimate2660 (2015).

5 Coumou, D. \& Robinson, A. Historic and future increase in the global land area affected by monthly heat extremes. Environmental Research Letters 8, 034018 (2013).

6 Weitzman, M. L. Fat-Tailed Uncertainty in the Economics of Catastrophic Climate Change. Review of Environmental Economics and Policy 5, 275-292 (2011).

7 Stern, N. The Economics of Climate Change: The Stern Review. (HM Treasury, 2007).

8 Nordhaus, W. D. \& Boyer, J. Roll the DICE Again: Economic Models of GLobal Warming. (MIT Press, 1999).

9 Tol, R. S. J. Estimates of the Damage Costs of Climate Change. Part 2: Dynamic estimates. Environmental and Resource Economics 21, 25 (2002).

10 IPCC. in Climate Change 2014: Impacts, Adaptation, and Vulnerability. Part A: Global and Sectoral Aspects. Contribution of Working Group II to the Fifth Assessment Report of the Intergovernmental Panel on Climate Change (eds C.B. Field et al.) 1-32 (Cambridge University Press, 2014).

11 Ricke, K. L., Moreno-Cruz, J. B., Schewe, J., Levermann, A. \& Caldeira, K. Policy thresholds in mitigation. Nature Geosci 9, 5-6, doi:10.1038/ngeo2607 (2016).

12 Gastner, M. T. \& Newman, M. E. J. Diffusion-based method for producing density-equalizing maps. Proceedings of the National Academy of Sciences of the United States of America 101, 7499-7504, doi:10.1073/pnas.0400280101 (2004).

13 G. Flato et al. in Climate Change 2013: The Physical Science Basis. Contribution of Working Group I to the Fifth Assessment Report of the Intergovernmental Panel on Climate Change (eds T. F. Stocker et al.) (Cambridge University Press, Cambridge, U.K., 2013).

14 Leduc, M., Matthews, H. D. \& de Elia, R. Regional estimates of the transient climate response to cumulative $\mathrm{CO} 2$ emissions. Nature Clim. Change 6, 474-478, doi:10.1038/nclimate2913

http://www. nature.com/nclimate/journal/v6/n5/abs/nclimate2913.html\#supplementaryinformation (2016).

15 Collier, P. Wars, Guns, and Votes: Democracy in Dangerous Places. (Bodley Head, 2009).

16 Collier, P. The Bottom Billion: Why the Poorest Countries are Failing and What Can Be Done About It (Oxford University Press, 2007).

17 Frame, D. J. \& Hepburn, C. J. in CLimate Change and Common Sense: Essays in Honour of Tom Schelling (eds Robert W. Hahn \& Alistair Ulph) (Oxford University Press, 2011).

18 Lazarus, R. J. Super Wicked Problems and Climate Change: Restraining the Present to Liberate the Future. Cornell Law Review 94, 1153-1234 (2009). 